\title{
Gastric emptying of different meal volumes of identical composition in preterm infants: a time series analysis
}

\author{
Sharon L. Perrella ${ }^{1}$, Anna R. Hepworth ${ }^{1}$, Zoya Gridneva ${ }^{1}$, Karen N. Simmer ${ }^{2}$, Peter E. Hartmann ${ }^{1}$ and Donna T. Geddes ${ }^{1}$
}

BACKGROUND: Preterm infants' meals typically progress to higher volumes over time. Knowledge of gastric emptying (GE) responses to differing meal volumes may inform enteral feeding management. We examined the effect of meal volume and composition on preterm GE.

METHODS: Forty infants were studied at $33.3 \pm 1.4$ (29.7-35.6) weeks postmenstrual age when fully enteral fed (target $150 \mathrm{ml} / \mathrm{kg} /$ day). Intraindividual comparisons of GE were made for paired meals of $100 \%$ and $75 \%$ prescribed volume and identical composition of mother's own milk $(n=21)$ and pasteurized donor human milk $(n=19)$. Serial stomach ultrasound images were used to calculate gastric residual volumes (GRVs) and remaining meal proportions (\% meal).

RESULTS: GE was faster in the early postprandial period and slowed over time $(P<0.001)$. Reduced volume meals had slower GE rates and lower GRV $(P<0.001)$. Serial postprandial $\%$ meal was similar between reduced and full volume meals $(P=0.41)$. Higher milk casein concentration was associated with slower GE $(P=0.04)$. Complete gastric emptying $(G R V=0 \mathrm{ml})$ was more common in infants fed at $3 \mathrm{~h}$ intervals compared with those fed every $2 \mathrm{~h}(P=0.002)$.

CONCLUSION: Early postprandial GE is more rapid for larger meal volumes. Stable preterm infants may tolerate feeding of a $3 \mathrm{~h}$ meal volume at shorter intervals.

$\mathbf{P}$ reterm infants' individual meal volumes are determined by both the prescribed $24 \mathrm{~h}$ volume, which increases to meet the nutritional needs of the growing preterm infant, and the prescribed meal interval. Delivery of full enteral nutrition to the very-low birth weight infant typically commences with lower meal volumes at $2 \mathrm{~h}$ intervals that advance when the infant is considered able to tolerate higher volumes at longer intervals (1). Meal volumes are often reduced in response to feeding intolerance, a common preterm complication characterized by signs of delayed gastric emptying (GE) (2). However, the influence of meal volume on GE and time to attainment of an empty stomach (residual volume $=0 \mathrm{ml}$ ) is not known. Knowledge of the effect of meal volume on GE in stable preterm infants will contribute to better management of enteral feeding.

There is limited evidence to inform GE of differing meal volumes in infants; published studies have examined only newborn preterm infants transitioning to full enteral nutrition. These studies used a proxy measure of gastric volume, the gastric half emptying time $\left(T \frac{1}{2}\right)$. Similar $T \frac{1}{2}$ were estimated for human milk meals of differing volumes, suggesting constant proportions of the prescribed meal volumes emptying over time for preterm neonates $(3,4)$. The reliability of the published findings is limited by long inter-test meal intervals, nonvalidated measurement methods, and test meals that were not matched for composition. Limited evidence from pediatric, adult, and animal model studies indicates that the early postprandial GE rate $(\mathrm{ml} / \mathrm{min})$ is faster for liquid meals of higher volume, with comparable $T \frac{1}{2}$ observed between meals of differing volumes. (5-7).

Meal composition influences GE, and although human milk is the preferred source of nutrition for preterm infants, its composition varies within and between women. Further, pasteurization and fortification appear to influence GE to a degree $(8,9)$. Previous studies of the effects of volume on GE in preterm infants included test meals of mother's own milk (MOM) or pasteurized donor human milk (PDHM); however these studies did not match or account for composition.

Our study aimed to determine whether GE in stable fully enteral-fed preterm infants differs between meals of identical composition, but differing volumes, and whether interindividual differences were related to differences in meal composition. Further, the study examined GE curves in preterm infants.

\section{METHODS}

We recruited medically stable infants born between 28 and 34 weeks of gestation from the neonatal nurseries of King Edward Memorial Hospital, Western Australia. Infants were fully enteral-fed MOM or PDHM with a target volume of $150 \mathrm{ml} / \mathrm{kg} /$ day as per hospital clinical practice guidelines. See Supplementary Table S1 (online). For fortified meals, one of the two bovine whey-based powdered human milk fortifiers (HMFs) was used as per the manufacturer's instructions: either S-26 HMF containing intact whey protein (Wyeth Nutrition, Baulkham Hills, NSW, Australia) or FM 85 HMF containing extensively hydrolyzed whey protein (Nestlé

\footnotetext{
${ }^{1}$ School of Molecular Sciences, The University of Western Australia, Crawley, Perth, Western Australia, Australia; ${ }^{2}$ Centre for Neonatal Research and Education, School of Paediatrics and Child Health, The University of Western Australia, Crawley, Perth, Western Australia, Australia. Correspondence: Sharon L. Perrella (sharon.perrella@uwa.edu.au) Received 29 May 2017; accepted 1 November 2017; advance online publication 20 December 2017. doi:10.1038/pr.2017.292
} 
Nutrition, Rhodes, NSW, Australia). Infants with congenital abnormalities or gastrointestinal disease within the previous $24 \mathrm{~h}$ were excluded. For multiple birth infants, one sibling was invited to participate. Ethics Committees of the Women and Newborn Health Service and The University of Western Australia approved the study, and parents provided informed consent.

Consecutive meals of differing volumes, but identical composition were studied; one $100 \%$ (full meal) and the other $75 \%$ of the prescribed meal volume (reduced meal). As per standard practice of the study hospital, each test meal was decanted from the infant's allocated refrigerated human milk immediately after the previous meal (2-3 h prior) and stored at bedside until gravity fed via an intragastric tube. The infants were offered a pacifier during meal delivery at the discretion of the nurse, and remained in the same body position throughout the study period.

Using the methods previously described (10), serial ultrasound stomach images were recorded with a 5PI phased array transducer (Sonologic SonoScape S6, Brisbane, QLD, Australia) immediately pre- and post-meal (T0) delivery, at $30 \mathrm{~min}$ postprandial (T30) and every $30 \mathrm{~min}$ thereafter until the next meal was due, i.e., until T90 for meals of $2 \mathrm{~h}$ interval, and T150 for meals of $3 \mathrm{~h}$ interval. The duration of each scan was $<3$ min. Images were saved on the ultrasound machine and subsequently transferred to a laptop computer for measurement.

Image measurements of the longitudinal, transverse, and anteroposterior axes were made using "Screen Calipers", V. 4.0 (Iconico, New York, NY) by the first author, who was blinded to details other than the infants' study identification numbers and study dates. Stomach volume or gastric residual volume (GRV) was calculated using the following equation, which has been assessed to have adequate repeatability and reliability (10): spheroid: longitudinal axis $\times$ antero-posterior axis $\times$ transverse axis $\times 0.52$ (11).

The remaining proportion of the delivered meal volume (\% meal) was determined for each postprandial measurement using the following equation:

$$
\frac{\text { gastric residual volume }}{\text { delivered meal volume }} \times 100
$$

Unfortified milk samples $(3-5 \mathrm{ml})$ were collected from the infant's daily allocation of expressed milk on the morning of the study, stored in sterile polypropylene-capped tubes (Sarstedt, Nümbrecht, Germany) at $4{ }^{\circ} \mathrm{C}$, then frozen at $-20^{\circ} \mathrm{C}$. Casein and whey proteins were separated by the method described by Kunz and Lonnerdal (12) and Khan et al. (13). Protein concentrations (total protein, casein, and whey proteins) were measured using the Bradford Protein Assay adapted by Mitoulas et al. (14). Fat concentrations were determined by the creamatocrit method (15), which has been validated against the spectroscopic esterified fat assay method (14).

Lactose concentrations were measured using the enzymatic spectrophotometric method of Kuhn and Lowenstein (16), adapted by Mitoulas et al. (14). Energy concentrations were calculated using the conversion factors of $9.0 \mathrm{kcal} / \mathrm{g}$ for fat, and $4.0 \mathrm{kcal} / \mathrm{g}$ for both protein and lactose (17).

The total biochemical and energy concentrations of fortified feeds were calculated by adding the HMF manufacturers' composition data to the measured unfortified human milk concentrations and expressed as grams per litre $(\mathrm{g} / \mathrm{l})$ and calories per $30 \mathrm{ml}(\mathrm{cal} / 30 \mathrm{ml})$ for each paired feed.

\section{Statistical Analysis}

Infants were recruited as part of a larger study (18). Analysis completed subsequent to recruitment for this study indicated that a sample size of 14 paired meals per milk type was sufficient to detect intraindividual differences in GE.

Analyses were performed using R 2.15.2 for Mac OSX (19). The nlme package was used for linear-mixed effects modeling (20). Descriptive statistics are presented as mean \pm SD (range) unless

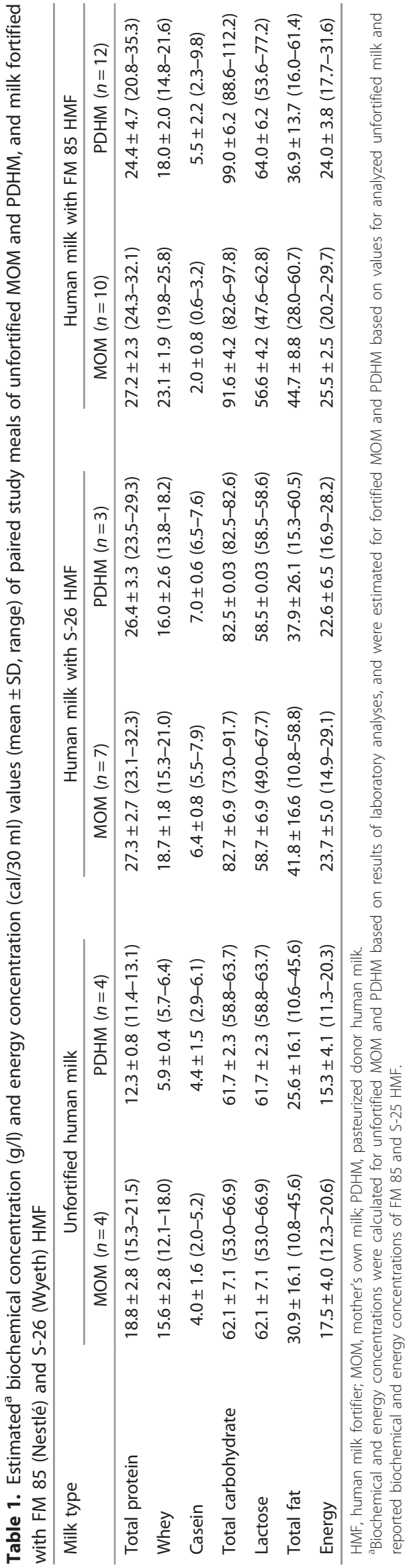




\section{Articles $\mid$ Perrella et al.}

otherwise specified. Model parameters are presented as coefficients (coeff.) and standard errors (SEs).

Linear-mixed modeling was used to determine the effect of a reduced meal volume (predictor) on serial postprandial GRV and \% meal. Random effects were fitted for meals within infants; this was significantly better than grouping by infant $(P<0.001)$. Random effects considered were different intercepts, different linear trends, and different quadratic curves. Initial model fitting showed that different quadratic curves for each feed within each infant were the best fit to the data; all reported parameters come from models with these random effects. Fitting of random effects by infant allowed us to control for influences on preterm GE that may differ between subjects including body position, infant age, milk composition, pasteurization, and fortification status $(8,21)$. Nonlinear changes in postprandial time were modeled using time as a $2^{\circ}$ polynomial based on our previous work (18). Appropriateness of the final models was assessed with standard residual plots.

Effect of reduced meal volume was assessed with postprandial time and meal condition (100\% and $75 \%$ prescribed volume) variables as fixed effects. Effects of milk composition/type were assessed with a set of models containing reduced volume, postprandial time, and one composition variable. Significant time by feed condition interactions were considered to indicate an effect of the meal condition on GE; significant interactions between meal condition and meal composition variables were considered to indicate differing effects of volume with composition differences.

Differences with respect to meal intervals in frequencies of empty stomachs (stomach volume $=0 \mathrm{ml}$ ) were tested for using Fisher's Exact Test.

\section{RESULTS}

\section{Infant and Meal Characteristics}

Studies of paired feeds of full and reduced volume, but identical milk type (MOM or PDHM) and composition in 45 infants resulted in usable data for 40 infants. Data were missing for one or both study meals due to equipment failure $(n=4)$, and one infant's data were excluded due to a large discrepancy in the durations of meal delivery. Of the 40 paired

a

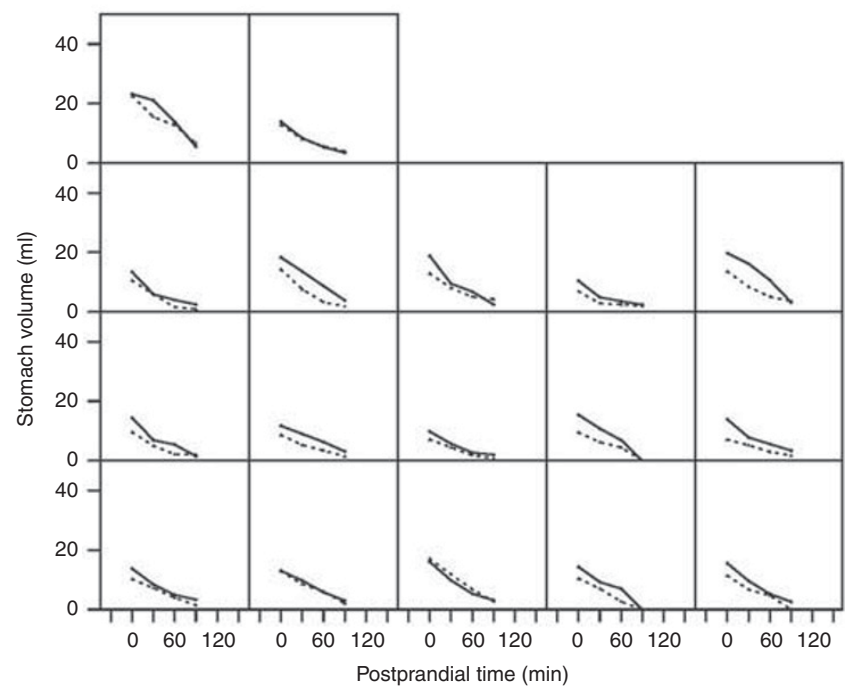

study meals examined, there were 21 MOM meals $(n=17$ fortified) and 19 PDHM meals ( $n=15$ fortified). As per the standard practice in the study hospital, infants weighing $<1,400 \mathrm{~g}$ were fed at $2 \mathrm{~h}$ intervals $(n=17)$ with the remainder fed at $3 \mathrm{~h}$ intervals $(n=23)$; infants $<35$ weeks PMA were fed in the prone or side-lying position $(n=27)$ with the remainder fed in the supine position. Duration of meal delivery by the gravity technique was 11.8 (5-25) min. Infant handling through the provision of routine care or examination before the next feed precluded data collection at T150 for 10 meals of $3 \mathrm{~h}$ intervals. Infant (19 female, 21 male) characteristics were: birth GA $30 \pm 1.5$ weeks (28-32.9 weeks); birth weight $1,428 \pm 387 \mathrm{~g}$ (895-2390 g); PMA $33.3 \pm 1.4$ weeks (29.7-35.6 weeks); weight $1,753 \pm 395 \mathrm{~g}(1,135-3,055 \mathrm{~g})$; and postnatal age 22 days \pm 9.3 (6-42 days). Six infants were born small for gestational age (SGA); eight received nasal CPAP at the time of the study. Five infants used a pacifier during meal delivery. None of the infants' prescribed medications are known to influence GE. Prescribed and reduced meal volumes were: $2 \mathrm{~h}$ interval $13.4 \mathrm{ml} / \mathrm{kg}(10-15 \mathrm{ml} / \mathrm{kg})$ and $9.9 \mathrm{ml} / \mathrm{kg}(8-11 \mathrm{ml} / \mathrm{kg})$, and $3 \mathrm{~h}$ interval $20.2 \mathrm{ml} / \mathrm{kg}(18-23 \mathrm{ml} / \mathrm{kg})$ and $15.1 \mathrm{ml} / \mathrm{kg}$ $(13-18 \mathrm{ml} / \mathrm{kg})$, respectively. Meal composition is reported in Table 1.

\section{GRV}

GRV reduced across the postprandial period $(P<0.001)$. Compared to full meals, the reduced meals had lower residual volumes $(P<0.001)$ and emptied at a slower rate $(P<0.001$, Figure 1). Higher casein concentration was associated with higher GRV $(0.33 \pm 0.16, P=0.04)$, while higher fat concentration was associated with a lower GRV $(-0.05 \pm 0.02$, $P=0.04)$. Fortification status, meal energy concentration,

b

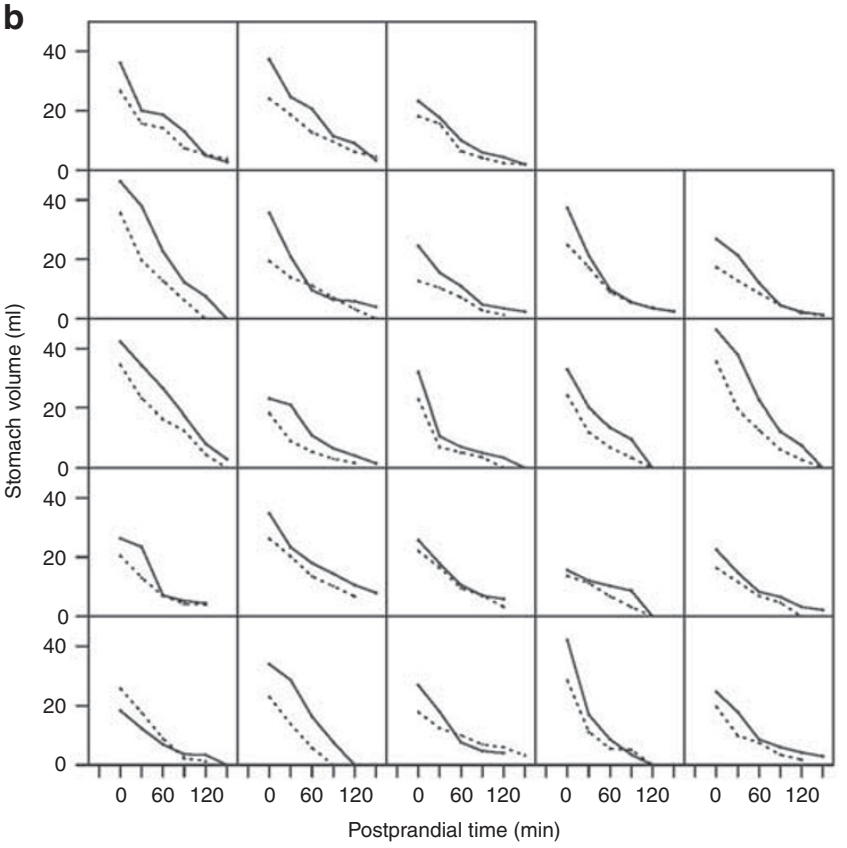

Figure 1. Postprandial gastric volumes for paired meals of $100 \%$ and $75 \%$ prescribed volume fed to preterm infants at (a) $2 \mathrm{~h}$ and (b) $3 \mathrm{~h}$ intervals. 


\section{Effect of volume on gastric emptying $\quad$ Articles}

Table 2. Parameter estimates (coeff.) and standard errors (SE) for meal volume and composition models

\begin{tabular}{|c|c|c|c|c|}
\hline & \multicolumn{2}{|c|}{ Gastric residual volume (ml) } & \multicolumn{2}{|c|}{ Proportion of prescribed meal (\% meal) } \\
\hline & coeff. \pm SE & $P$ value & coeff. \pm SE & $P$ value \\
\hline \multicolumn{5}{|l|}{ Meal condition and time ${ }^{a}$} \\
\hline Intercept & $18.2 \pm 1.63$ & & $79.3 \pm 3.0$ & \\
\hline \multicolumn{5}{|l|}{$75 \%$ meal volume } \\
\hline Main effect & $-4.5 \pm 0.7$ & $<0.001$ & $-1.7 \pm 2.0$ & 0.41 \\
\hline Interaction with (time) ${ }^{\mathrm{a}}$ & $0.042 \pm 0.006$ & $<0.001$ & $6.0 \times 10^{-5} \pm 0.020$ & 1.00 \\
\hline \multicolumn{5}{|l|}{ Postprandial time } \\
\hline Linear & $-0.28 \pm 0.018$ & $<0.001$ & $-1.0 \pm 0.05$ & $<0.001$ \\
\hline Quadratic & $0.0008 \pm 0.00008$ & $<0.001$ & $0.003 \pm 0.0002$ & $<0.001$ \\
\hline \multicolumn{5}{|l|}{ Composition and milk type ${ }^{\mathrm{b}}$} \\
\hline \multicolumn{5}{|l|}{ Meal characteristics } \\
\hline \multicolumn{5}{|l|}{ Human milk fortifier } \\
\hline S-26 fortifier & $-0.28 \pm 0.99$ & 0.78 & $-0.9 \pm 3.0$ & 0.76 \\
\hline FM 85 fortifier & $-0.72 \pm 0.72$ & 0.42 & $-1.0 \pm 2.7$ & 0.72 \\
\hline PDHM & $1.23 \pm 0.66$ & 0.069 & $3.8 \pm 2.0$ & 0.063 \\
\hline \multicolumn{5}{|l|}{ Meal composition $g /{ }^{\mathbb{C}}$} \\
\hline Carbohydrate & $-0.01 \pm 0.03$ & 0.70 & $0.02 \pm 0.07$ & 0.77 \\
\hline Lactose & $0.06 \pm 0.06$ & 0.30 & $0.2 \pm 0.2$ & 0.33 \\
\hline Total protein & $0.02 \pm 0.07$ & 0.72 & $0.1 \pm 0.2$ & 0.68 \\
\hline Casein & $0.33 \pm 0.16$ & 0.04 & $1.0 \pm 0.4$ & 0.035 \\
\hline Whey & $-0.05 \pm 0.07$ & 0.49 & $-0.1 \pm 0.2$ & 0.69 \\
\hline Fat & $-0.05 \pm 0.02$ & 0.039 & $-0.1 \pm 0.1$ & 0.11 \\
\hline Meal energy $\mathrm{kcal} / 30 \mathrm{ml}$ & $-0.12 \pm 0.07$ & 0.10 & $-0.2 \pm 0.2$ & 0.28 \\
\hline
\end{tabular}

Parameter estimates (coeff.) \pm standard errors (SE) for variables that are predictive of gastric volumes (ml). Values for significant predictors (final model) are from a single multivariate model; other values are from a sequence of multivariate models with all predictors from the final model, plus the variable in the row.

PDHM, pasteurized donor human milk.

a Model for \% meal includes nonsignificant variables to allow for appropriate comparison with GRV model.

bSignificance of each of the composition variables when added as main effect to the meal condition and time model. Reference level for fortification = "none".

${ }^{c}$ Meal composition analyses run for $n=35$ infants due to missing analysis samples.

other composition factors, and pacifier use $(P=0.24)$ did not impact GRV. For each additional minute of meal delivery duration, the GRV increased by $0.12 \mathrm{ml}(P=0.047)$. There was no interaction between meal volume and the $2^{\circ}$ polynomial term for gastric volume measurements $(P=0.15)$, indicating that differences in meal volume did not change the shape of the GE curve. Therefore, coefficient estimates and standard errors for the linear term are presented in Table 2.

\section{Proportion of delivered meal volume (\% meal)}

The $\%$ meal consistently decreased across the postprandial period $(P<0.001)$, with the GE rate slowing over time $(P<0.001$, Figure 2). The \% meal did not differ between meals of full and reduced prescribed volume $(P=0.41)$. Higher casein concentration was associated with higher \% meal $(1.0 \pm 0.4, P=0.04)$. Fortification status, milk type, meal energy, other composition factors, meal delivery duration $(P=0.13)$, and pacifier use $(P=0.84)$ did not impact \% meal.
No interaction was found between meal volume and the $2^{\circ}$ polynomial term for \% meal $(P=0.35)$. Coefficient estimates and standard errors for the linear term model are presented in Table 2.

Final residual stomach volumes were measured within 30 min of the next meal delivery, i.e., T90 and T150 for meals of 2 and $3 \mathrm{~h}$ intervals, respectively. Where there were measurable stomach volumes, the residual volumes were $2.4 \pm 1.6 \mathrm{ml}(0-6.7 \mathrm{ml})$ at $\mathrm{T} 90$ and $1.8 \pm 1.9 \mathrm{ml}(0-8.0 \mathrm{ml})$ at T150 for meal intervals of 2 and $3 \mathrm{~h}$, respectively. The incidence of empty stomachs $(0 \mathrm{ml})$ was lower for meals of $2 \mathrm{~h}$ intervals than those of $3 \mathrm{~h}$ intervals ( $5 / 34$ vs. $18 / 36, P=0.002$ ). Further, empty stomachs were identified in $11 / 46$ of $3 \mathrm{~h}$ interval meals at $120 \mathrm{~min}$ postprandial.

\section{DISCUSSION}

This is the first study to compare emptying of differing meal volumes of identical composition using multiple matched time points and precise validated measurement methods. Our 


\section{Articles $\mid$ Perrella et al.}

a

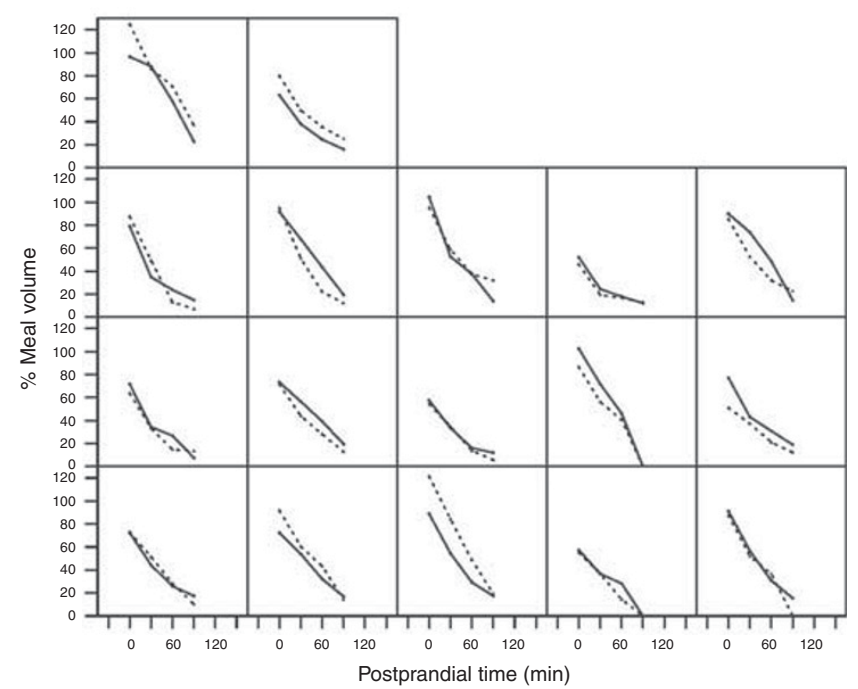

b

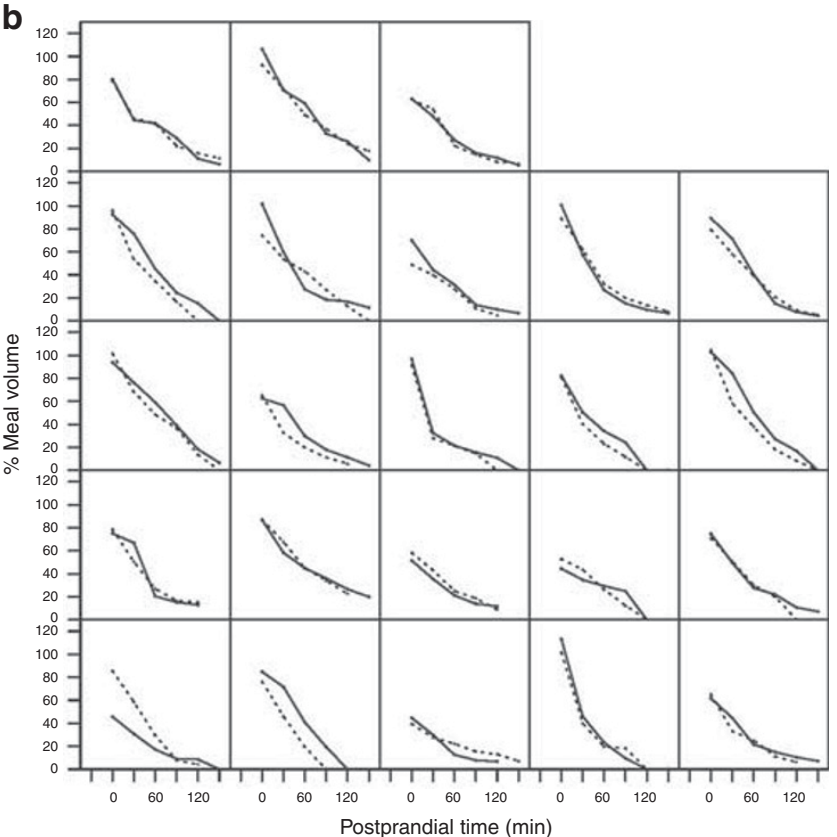

Figure 2. Postprandial proportions of delivered meal volume for paired meals of $100 \%$ and $75 \%$ prescribed volume fed to preterm infants at (a) $2 \mathrm{~h}$ and (b) $3 \mathrm{~h}$ intervals.

findings confirm that the proportions of the meal emptied across the postprandial period did not differ for reduced meal volumes (Figure 2). Although GRV differed between full and reduced volume meals, the differences were not of a magnitude to be of clinical relevance (Figure 1).

Meals of higher volume had a faster rate of emptying $(\mathrm{ml} /$ min) early in the postprandial period and slowed over time (Figure 1). This pattern of GE in preterm infants, previously observed by our group (8), is similar to that reported in pediatric and adult studies (5-7). This response was not influenced by pacifier use during enteral feeding. There was a negligible effect of meal delivery duration on GRV, likely reflecting the longer delivery time and concurrent emptying of larger meal volumes. Our findings, therefore, suggest that the preterm infant has a mature GE response to liquid meal volume.

The similar postprandial \% meal observed between human milk meals of full and reduced volumes are also in agreement with reports of similar $T \frac{1}{2}$ between meals of differing volumes in preterm infants $(3,4,22)$. However this is the first study to examine the effect of meal volume using the recommended source of preterm nutrition, i.e., MOM, and in its absence, PDHM. Previous studies have included only 10 subjects using diluted human milk or formula meals $(3,22)$ or PDHM meals that have not been matched for composition (4).

Higher milk casein concentrations were associated with residual volumes $0.33 \pm 0.16 \mathrm{ml}$ higher $(P=0.04)$ and $\%$ meal $1.0 \pm 0.4 \%$ higher $(P=0.035)$ for each additional $1 \mathrm{~g} / \mathrm{l}$ casein, whereas higher milk fat concentration was associated with a residual volume $-0.05 \pm 0.02 \mathrm{ml}$ lower for each additional $1 \mathrm{~g} /$ 1 fat concentration $(P=0.039)$. However, the magnitudes of the differences are very small, and therefore we believe are not clinically relevant. The higher residual volumes and \% meal observed for PDHM meals were not statistically significant, and HMF did not impact GE (Table 2).

The $25 \%$ volume difference in the paired study meals is similar to the $33 \%$ volume difference between prescribed meals of 2 and $3 \mathrm{~h}$ intervals. It is therefore likely that whether an individual preterm infant is fed the volume of a 2 or $3 \mathrm{~h}$ interval meal under similar conditions, e.g., same body positioning and meal composition, the $T \frac{1}{2}$ and indeed the remaining \% meal will be similar at any postprandial time point.

Although GE patterns are similar between paired meals of differing volumes, but identical milk type, PDHM meals tended to empty more slowly than MOM, although the difference was not statistically significant (Table 2). This contrasts with our previous study, which showed that meals of PDHM meals empty significantly more slowly than MOM (8). Both studies examined interindividual rather than intraindividual differences in GE of PDHM and MOM. It is possible that the results may be confounded by interindividual factors such as infant age and body position. Evaluation of GE of PDHM and MOM within individual infants is needed to definitively determine whether GE differs by milk type.

Our results indicated that fortification of human milk with FM 85 HMF did not affect GE. This finding contrasts with our previous work (21), where intraindividual differences in GE of fortified and unfortified MOM meals were specifically examined. The current study examined intraindividual differences in GE of meal of differing volumes and identical composition, and therefore comparisons of fortified and unfortified meals were made between infants. This likely explains why the subtle differences in GE of unfortified and FM 85 fortified meals were not detected. 
Our finding of a higher incidence of empty stomachs following meals of $3 \mathrm{~h}$ intervals $(8,21)$, together with evidence of infants cuing for meals before the scheduled time suggest that increased meal frequency and/or volume may be appropriate for some infants (23). For example, for a $1,600 \mathrm{~g}$ infant fed $150 \mathrm{ml} / \mathrm{kg} /$ day as $30 \mathrm{ml}$ at $3 \mathrm{~h}$ intervals, the stomach has typically emptied to a minimal residual volume or is completely empty by $2.5 \mathrm{~h}$ postprandial. It is possible that the infant may tolerate feeding of a $30 \mathrm{ml}$ volume at $2.5 \mathrm{~h}$ intervals, essentially increasing the total daily intake to $170 \mathrm{ml} / \mathrm{kg} /$ day. Such increases in delivered $24 \mathrm{~h}$ volumes would result in a higher nutrient intake and subsequently enhanced postnatal growth.

Semi-demand feeding may also offer a suitable alternative strategy, whereby meals are scheduled, but the infant is offered a meal earlier in response to feeding cues, or is gavagefed if sleeping when the meal is due (24). Semi-demand feeding is potentially associated with earlier attainment of full oral feeding $(25,26)$ and earlier discharge from hospital $(23,24)$. Further evaluation of the effects of this feeding method on infant outcomes is warranted.

Our findings are limited to healthy preterm infants receiving full enteral nutrition. GE responses in infants with feeding intolerance, those receiving partial parenteral nutrition, and those with comorbidities remain to be investigated.

\section{CONCLUSIONS}

For fully enteral-fed preterm infants, GE of human milk meals occurs in a curvilinear manner with the rate of emptying slowing over time, irrespective of meal volume. Although a statistically significant difference in gastric residual volumes was observed between meals with volume differences of $25 \%$, the volume differences were very small and unlikely to be considered clinically relevant. Composition differences in human milk meals have marginal impact on GRV and \% meal. Our data suggest that a meal interval of $2-3 \mathrm{~h}$ is appropriate for healthy fully enteral-fed preterm infants, and some may tolerate meal intervals of $<3 \mathrm{~h}$ without changes to meal volume, thus improving nutrient intake.

\section{SUPPLEMENTARY MATERIAL}

Supplementary material is linked to the online version of the paper at http://www.nature.com/pr

\section{STATEMENT OF FINANCIAL SUPPORT}

D.T.G. receives an unrestricted research grant from Medela AG, from which S.L.P., A.R.H., and Z.G. receive salaries.

Disclosure: The authors declare no conflict of interest.

\section{REFERENCES}

1. DeMauro SB, Abbasi S, Lorch S. The impact of feeding interval on feeding outcomes in very low birth-weight infants. J Perinatol 2011;31:481-6.

2. Moore TA, Wilson ME. Feeding intolerance: a concept analysis. Adv Neonatal Care 2011;11:149-54.

3. Ramirez A, Wong WW, Shulman RJ. Factors regulating gastric emptying in preterm infants. J Pediatr 2006;149:475-9.
4. Pozler O, Neumann D, Vorisek V, Bukac J, Bures J, Kokstein Z. Development of gastric emptying in premature infants. Use of the (13)Coctanoic acid breath test. Nutrition 2003;19:593-6.

5. Kwiatek MA, Menne D, Steingoetter A, et al. Effect of meal volume and calorie load on postprandial gastric function and emptying: studies under physiological conditions by combined fiber-optic pressure measurement and MRI. Am J Physiol Gastrointest Liver Physiol 2009;297:G894-901.

6. McHugh PR, Moran TH. Calories and gastric emptying: a regulatory capacity with implications for feeding. Am J Physiol 1979;236:R254-60.

7. Schmitz A, Kellenberger CJ, Lochbuehler N, et al. Effect of different quantities of a sugared clear fluid on gastric emptying and residual volume in children: a crossover study using magnetic resonance imaging. Br J Anaesth 2012;108:644-7.

8. Perrella SL, Hepworth AR, Gridneva Z, Simmer KN, Hartmann PE, Geddes DT. Gastric emptying and curding of pasteurized donor human milk and mother's own milk in preterm infants. J Pediatr Gastroenterol Nutr 2015;61:125-9.

9. Ewer AK, Yu VY. Gastric emptying in pre-term infants: the effect of breast milk fortifier. Acta Paediatr 1996;85:1112-5.

10. Perrella SL, Hepworth AR, Simmer KN, Geddes DT. Validation of ultrasound methods to monitor gastric volume changes in preterm infants. J Pediatr Gastroenterol Nutr 2013;57:741-9.

11. Lambrecht L, Robberecht E, Deschynkel K, Afschrift M. Ultrasonic evaluation of gastric clearing in young infants. Pediatr Radiol 1988;18:314-8.

12. Kunz C, Lonnerdal B. Human milk proteins: separation of whey proteins and their analysis by polyacrylamide gel electrophoresis, fast protein liquid chromatography (FPLC) gel filtration, and anion-exchange chromatography. Am J Clin Nutr 1989;49:464-70.

13. Khan S, Casadio YS, Lai CT, et al. Investigation of short-term variations in casein and whey proteins in breast milk of term mothers. J Pediatr Gastroenterol Nutr 2012;55:136-41.

14. Mitoulas LR, Kent JC, Cox DB, Owens RA, Sherriff JL, Hartmann PE. Variation in fat, lactose and protein in human milk over $24 \mathrm{~h}$ and throughout the first year of lactation. Br J Nutr 2002;88:29-37.

15. Fleet IR, Linzell JL. A rapid method of estimating fat in very small quantities of milk. J Physiol 1964;175:15-7.

16. Kuhn NJ, Lowenstein JM. Lactogenesis in the rat. Changes in metabolic parameters at partuition. Biochem J 1967;105:995-1002.

17. Neville MC, Jensen RG. Volume and caloric density of human milkIn: Jensen RGed. Handbook of Milk Composition. San Diego: Academic Press, 1995: 99-113.

18. Perrella SL, Hepworth AR, Simmer KN, Hartmann PE, Geddes DT. Repeatability of gastric volume measurements and intragastric content using ultrasound in preterm infants. J Pediatr Gastroenterol Nutr 2014;59:254-63.

19. R Core Team. R: A Language and Environment for Statistical Computing. Vienna, Austria: R Core Team, 2012.

20. Pinheiro J, Bates D, DebRoy S, Sarkar D. R Core Team. nlme: Linear and Nonlinear Mixed Effects Models. R package version 3.1-105 ed2012.

21. Perrella SL, Hepworth AR, Simmer KN, Geddes DT. Influences of breast milk composition on gastric emptying in preterm infants. J Pediatr Gastroenterol Nutr 2015;60:264-71.

22. Riezzo G, Indrio F, Raimondi F, et al. Maturation of gastric electrical activity, gastric emptying and intestinal permeability in preterm newborns during the first month of life. Ital J Pediatr 2009;35:6.

23. Puckett B, Grover VK, Holt T, Sankaran K. Cue-based feeding for preterm infants: a prospective trial. Am J Perinatol 2008;25:623-8.

24. McCormick FM, Tosh K, McGuire W. Ad libitum or demand/semidemand feeding versus scheduled interval feeding for preterm infants. Cochrane Database Syst Rev 2010: CD005255.

25. McCain GC, Del Moral T, Duncan RC, Fontaine JL, Pino LD. Transition from gavage to nipple feeding for preterm infants with bronchopulmonary dysplasia. Nurs Res 2012;61:380-7.

26. Kirk AT, Alder SC, King JD. Cue-based oral feeding clinical pathway results in earlier attainment of full oral feeding in premature infants. J Perinatol 2007;27:572-8. 